\title{
Kernos
}

Revue internationale et pluridisciplinaire de religion grecque antique

9 | 1996

Varia

\section{Pour une approche du panthéon argien par la mythologie : le bouclier d'Athéna}

\section{Marcel Piérart}

\section{(2) OpenEdition \\ Journals}

\section{Édition électronique}

URL : http://journals.openedition.org/kernos/1166

DOI : 10.4000/kernos. 1166

ISSN : 2034-7871

\section{Éditeur}

Centre international d'étude de la religion grecque antique

\section{Édition imprimée}

Date de publication : 1 janvier 1996

ISSN : 0776-3824

\section{Référence électronique}

Marcel Piérart, « Pour une approche du panthéon argien par la mythologie : le bouclier d'Athéna », Kernos [En ligne], 9 | 1996, mis en ligne le 21 avril 2011, consulté le 20 avril 2019. URL : http:// journals.openedition.org/kernos/1166; DOI : 10.4000/kernos.1166 


\title{
Pourr une approche du panthéon argien par la mythologie : le bouclier d'Athéna*
}

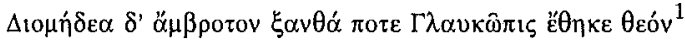

Dans le cas d'Argos, il est possible d'établir des relations entre les généalogies royales et la distribution géographique des mythes qui viennent s'y greffer. On s'en convaincra aisément en analysant les récits regroupés autour des dynasties d'Inachos et de Danaos. Pausanias distingue trois périodes dynastiques qui se sont succédé assez brutalement ${ }^{2}$ :

$1^{\circ}$ La dynastie d'Inachos, qui comprend neuf rois. S'y rattachent des figures comme Niobé et surtout Io. L'un des rois, Phorôneus, fils d'Inachos, passait à Argos pour avoir donné le feu aux mortels.

$2^{\circ}$ La période de la triple royauté. Danaos, venu d'Égypte, obtient la royauté à Argos. Quelques générations plus tard, Melampous, mandé pour guérir la maladie des filles de Proitos, obtient une part de la royauté pour son frère Bias et pour lui-même. De la lignée de Melampous naîtra Amphiaraos et de celle de Bias, Adraste. Par là, s'implantent à Argos les traditions liées au cycle thébain et au cycle troyen. D'autre part, le frère de Proitos, Akrisios, aura pour petit-fils Persée, qui est le bisaïeul d'Héraklès.

$3^{\circ}$ La période instaurée par Témenos et les autres Héraclides après la conquête faite aux dépens, non pas des dynasties précédentes, qui s'étaient éteintes, mais de Tisamenos, le fils d'Oreste. Ce dernier avait pu s'emparer d'Argos et de Lacédémone.

Les mythes qui se rattachent à la dynastie d'Inachos ont surtout affaire avec le nord de la plaine et le sanctuaire d'Héra. Ceux qui ont trait à Danaos et à ses filles se rapportent au sud-ouest de la plaine, à Lerne et à la région voisine.

\footnotetext{
Lors de mes recherches sur les légendes et les cultes traités ici, j'ai bénéficié d'échanges de vues avec W. Burkert en 1988 et 1990 et V. Pirenne-Delforge en 1995. Ils ne peuvent être tenus pour responsables des erreurs que j'ai commises. En 1988, j'ai pu encore prendre connaissance - et tirer profit - d'un mémoire, demeuré inédit à ce jour, de M.-F. Billot sur l'Héraion et les boucliers argiens. Si des divergences de vues subsistaient entre nous, elles tiendraient au caractère lacunaire des sources et non à l'érudition, digne de tous éloges, de ma collègue.

1 Pindare, Ném., X, 12-13. Cf. ci-dessous, n. 66.

2 Pausanias, II, 15, 4-16, 4; 18, 4-19, 2. Cf. ci-dessous, n. 4.
} 
Le clivage mythographique reflète le contraste observé entre la zone sèche et la zone marécageuse. Par exemple le mythe sur la dévolution du territoire d'Argos à Héra. Ainsi se dessinent deux «provinces culturelles » qui ont pour centre l'une, le sanctuaire d'Héra, l'autre, celui de Lerne. Elles correspondent à deux régions qui contrastent très vivement du point de vue hydrographique. Cette organisation de la matière mythique est très ancienne, comme en témoigne un vers du corpus hésiodique ${ }^{3}$ :

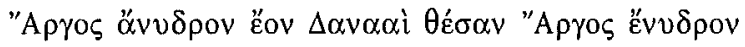

Argos privée d'eau doit aux Danaïdes d'être devenue Argos riche en eau.

Tout cela, j’ai déjà eu l'occasion de le dire ailleurs ${ }^{4}$, mais ce rappel était nécessaire pour justifier le présent propos. Si les généalogies formaient un principe classificatoire des mythes étiologiques qui se rapportent aux cultes et aux sanctuaires des divinités, il est possible d'aborder par elles l'étude du panthéon argien. Sans exclure d'autres voies d'approche ${ }^{5}$, l'organisation de la matière mythique fournit un moyen de comprendre l'importance accordée à chaque divinité, les cultes qui s'y rattachent et les relations qu'elle entretient avec les autres dans ces contextes précis. Dans quelques cas, elle permet d'orienter la recherche vers une explication de phénomènes que leur apparent isolement rendait difficile à comprendre.

L'exemple que je voudrais traiter ici est un rite argien apparemment isolé : lors du bain rituel de la déesse Athéna, on portait en cortège un bouclier que la légende attribuait à Diomède.

L'Hymne $\mathrm{V}$ de Callimaque décrit une cérémonie rituelle argienne : le bain de la statue de Pallas, conduite au fleuve sur un char tiré par des cavales. Elle était escortée par le bouclier de Diomède. Priant la déesse de venir, le poète s'adresse à elle en ces termes :

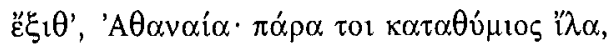

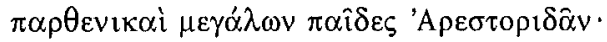

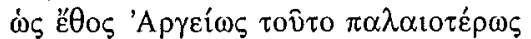

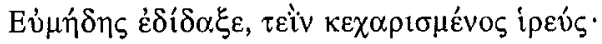

3 Fr. Hesiodea, 128 Merchelbach-West.

4 M. PIÉrart, "Argos assoiffée " et "Argos rtche en cavales", in M. PIÉRART (éd.), Polydipsion Argos, Paris-Fribourg, 1992, p. 119-146. - Voir mon article Les généalogies des rois d'Argos d'après Pausanias, à paraître dans les actes du colloque de Chantilly Généalogies mytbiques (septembre 1995).

5 Qu'il me suffise de rappeler ici combien l'étude de la diffusion d'une épiclèse comme Lykeios peut être éclairante pour l'histoire du culte dans une cité donnée: F. GRAF, Nordionische Kulte, Rome, 1985 , p. 219-225. 


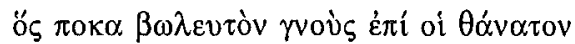

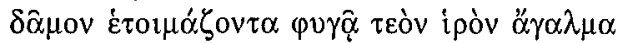

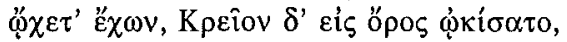

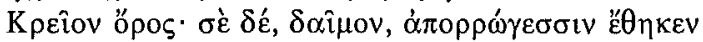

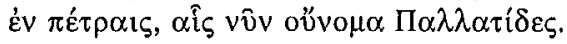

Athéna, viens à nous : vois ici la troupe, qui plaît à ton coeur, des vierges filles des puissants Arestorides. Athéna, on apporte le bouclier de Diomède : c'est l'us antique des Argiens, c'est le rite qu'Eumédès enseigna : Eumédès, ton prêtre favori, qui jadis surprenant le dessein meurtrier du peuple contre lui, s'enfuit, emportant ton image sainte, et s'établit sur le mont Kréion. Le mont Kréion, c'est là, déesse qu'il t'installa dans les escarpements rocheux qui s'appellent encore aujourd'hui les Pierres de Pallas (trad. E. Cahen modifiée).

\section{Les boucliers d'Héra}

Dans une ville qui se glorifiait de ses bronziers, le bouclier jouait un rôle important ${ }^{6}$. Il est certain qu'à l'époque impériale, le prix du concours des Héraia était un bouclier de bronze, qui finit par donner son nom au concours

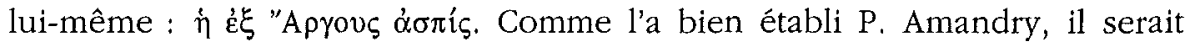
cependant aventureux de vouloir attribuer une connotation religieuse à cette appellation ${ }^{7}$. Le concours a changé plusieurs fois de nom. Le bouclier, qui a dû figurer assez tôt parmi les récompenses, n'a pas toujours été le seul prix décerné : au Ve siècle on offrait encore des objets divers (vases, trépieds). Le témoignage des scholies de Pindare ${ }^{8}$ est confirmé sur ce point par les sources archéologiques et épigraphiques.

\section{Le bouclier de Danaos}

Le mythe du bouclier de Danaos, que Lyncée fit dépendre du sanctuaire d'Héra pour l'offrir à Abas, constitue, sous la forme sous lequel nous le connaissons par des sources latines, l'aition du concours lorsqu'il s'appelait $\dot{\varepsilon} \xi$ "A $\dot{\alpha} \sigma \pi i \varsigma^{9}$. Les ennemis d'Abas étaient frappés de terreur à la seule vue de son

6 Sur ce qui suit, on consultera l'article de P. AMANDRY, Sur les concours argiens, in $B C H$ Suppl. VI (1980), p. 211-253; ID., Le bouclier d'Argos, in BCH, 107 (1983), p. 627-634. Les sources littéraires et épigraphiques y sont rassemblées et classées.

7 Comme le faisait I. RINGWOOD ARNOLD, The Shield of Argos, in A/A, 41 (1937), p. 436-440. F. DE POLIGNAC, La naissance de la cité grecque, Paris, 1984, p. 54, n’hésite pas à écrire que le « sanctuaire <de l'Héraion> était au cœur d'un vaste ensemble rituel et mythique concernant le bouclier $»$. Sur la procession d'hommes en armes, ci-dessous, n. 34.

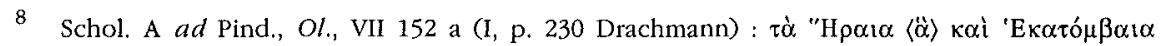

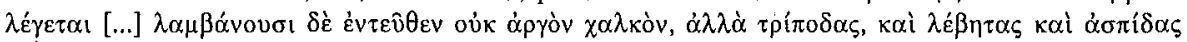

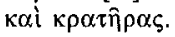

9 HYGIN, Fabulae, 170, 9-10; 273, 2. 
bouclier. Virgile, qui, comme l'ont bien vu les commentateurs ${ }^{10}$, connaissait la légende, s'y réfère à propos de la fondation mythique par Énée des Concours d'Actium créés par Octave en 28 : Énée serait entré de quelque manière en possession du bouclier d'Abas, qu'il aurait dédié à Actium après y avoir fait célébrer des concours par ses hommes ${ }^{11}$. Que le bouclier d'Abas puisse être évoqué dans le double contexte des concours d'Argos et d'Actium ne relève sans doute pas du hasard.

La légende du bouclier de Danaos est en contradiction avec celle du combat de ses arrière-petits-enfants Proitos et Acrisios, ces frères ennemis qui se battaient déjà dans le sein de leur mère et qui auraient inventé le bouclier rond pour mieux se faire la guerre. Hésychios connaissait une fête appelée Daulis $^{12}$ qui rappelait ce combat et Pausanias avait vu sur la route de Tirynthe le cénotaphe des combattants ${ }^{13}$. Mais nous ne savons pas en l'honneur de quelle divinité la fête se déroulait.

On ne s'étonnera donc pas qu'une autre étiologie du prix des concours d'Héra ait été proposée. Une scholie de Pindare en rapporte l'usage au roi Archinos, fondateur des concours en l'honneur d'Héra ${ }^{14}$ :

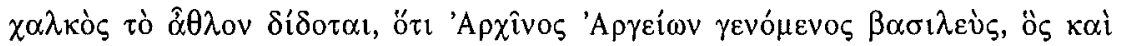

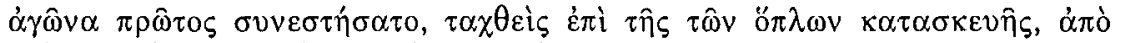

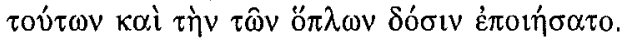

Le prix donné est en bronze parce qu'Archinos, devenu roi d'Argos, qui institua le premier le concours, préposé à la confection des armes, avait instauré à partir d'elles le don d'armes.

10 SERVIUS [auctus], ad Verg. Aen., III, 286. Virgile a omis d'expliquer comment Énée était entré en possession du bouclier d'Abas, mais l'allusion à la légende d'Abas était intentionnelle. Le commentateur ne s'y est pas trompé, qui raconte la légende d'Abas. La ville ayant été attaquée après la mort d'Abas, un jeune homme réussit à lui seul à mettre les ennemis en déroute : ...tunc senes el Abantis arma consecrata demonstrat bortatusque est ut eis uteretur; quibus tunc sumptis ituenis properat in actem. Hostes vero viso Abantis clipeo fugerunt. Quidam sane Abantem inventorem clipel ferunt. - Sur le rôle qu'Abas a pu jouer dans la tragédie Lyncée de Théodecte de Phasélis, qu'Aristote connaissait (Poétique, 11, 1452 a 27; 18, 1455 b 29-30), on en est réduit aux hypothèses.

11 VIRGILE, En., III, 286.

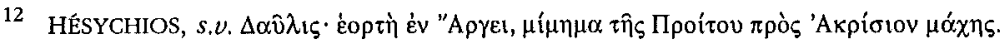

13 PAUSANIAS, II, 25, 7, qui rapporte aussi l'aition de l'invention du bouclier. La chrestomathie anonyne connue par $P . O x y ., 1241, \mathrm{~V}, 11-22$ (IIe s. ap. J.-C.) connaît les deux traditions.

14 Scholie BCEQ ad Pind., Ol., VI, 152d (I, p. 231 Drachmann). 
Alors que les textes - poétiques - des Ve-IVe siècles désignent le prix des concours comme « le bronze d'Argos ${ }^{15}$, ce qui pourrait s'appliquer à toutes sortes d'ustensiles, la scholie parle d'armes, donc vraisemblablement de boucliers. Archinos n'est connu autrement que par un stratagème de Polyen, qui raconte comment il devint tyran en faisant remettre par les Argiens leurs anciennes armes sous prétexte de les remplacer par des nouvelles ${ }^{16}$. Droysen le plaçait à l'époque de la guerre de Chrémonidès, vers $265^{17}$. Ce n'est guère possible, car nous savons maintenant que la cité était gouvernée au IIle siècle par des tyrans appelés Aristippos ou Aristomachos ${ }^{18}$. Le texte de la scholie n'est pas aberrant pour autant: Pheidon aussi fut présenté comme un roi devenu tyran $^{19}$. Les rois argiens, selon Pausanias, n'avaient pas de pouvoirs étendus ${ }^{20}$. Le point commun entre les deux textes est qu'Archinos s'occupait de l'approvisionnement des citoyens en armes. C'est un motif qui doit être relativement récent. Les deux récits, qui sont des reconstructions érudites, peuvent avoir figuré dans des Argolika classiques ou hellénistiques, attribuant à un roi Archinos, dont il faudrait rétablir le nom dans la liste des descendants de Témenos, qui passait pour avoir fondé les Héraia, l'institution de ce prix.

Les scholies de Pindare paraissent puiser dans des commentaires qui connaissaient le concours sous le double nom d'Hekatombaia et d'Héraia, mais

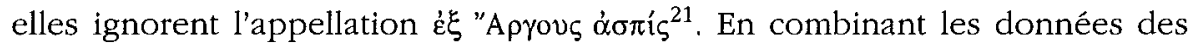
sources littéraires, des scholies et des inscriptions, on est conduit à suggérer la chronologie suivante :

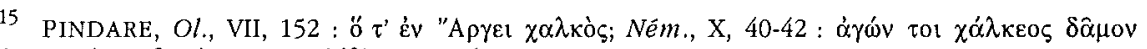

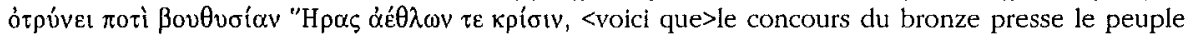
de se rendre à l'hécatombe d'Héra et au jugement des épreuves; $S E G, \mathrm{XXXV}(1985), 267,1,8$ : [-..-

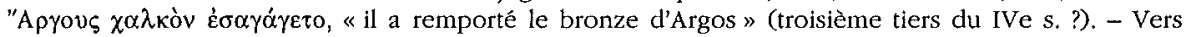
la même époque, l'épigramme pour le roi Nikokréon de Salamine de Chypre rappelle que les Argiens lui ont érigé une statue comme prix de leur reconnaissance à cause du métal qu'il envoyait

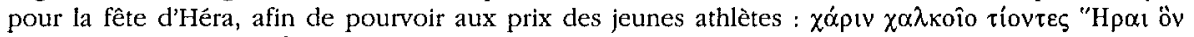

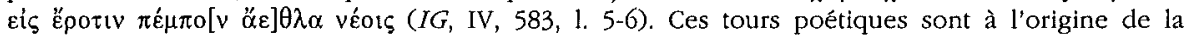

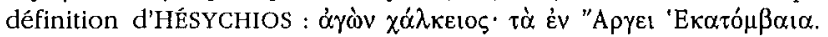

16 POLYEN, Hist. var., III, 8.

17 J.G. DROYSEN, G.d. Hellen, Gotha 1877-1878, III 1, p. 240. - M. MITSOS, Argoliki prosopograpbia, Athènes, 1952 , p. 47-48 pencherait plutôt pour le VIe s., à cause des analogies qu'il perçoit entre le coup d'Archinos et celui de Pisistrate.

18 Cf. A. WILHELM, Beiträge zur griech. Inschr., Vienne, 1909, nº 95, p. 110-112.

19 Tyran : Hérodote, VI, 127; roi devenu tyran : ARISTOTE, Pol, V, 10, 1310 b 26-28.

20 PAUSANIAS, II, 19, 2. Sur les traditions relatives aux Téménides, $c f$. P. CARLIER, La royauté en Grèce, Strasbourg, 1984, p. 384-395.

21 En plus du texte cité ci-dessus, n. 14-15, voir aussi les scholies ad Pind., Ol., VII 152 c, d (I, p. 130-131 Drachmann) et $P y t b$., VIII, 113c (II, p. 217 Drachmann). La dernière provient sûrement de Didyme, qui écrivait à l'époque d'Auguste ( $c f . J$. IRIGOIN, Histoire du texte de Pindare, Paris,

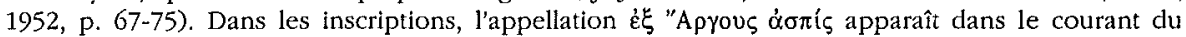
premier siècle de notre ère. 


\begin{tabular}{|c|c|c|}
\hline Nom du concours ${ }^{22}$ & Prix & Aition \\
\hline 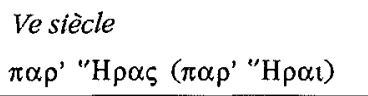 & Hydries, lébès, trépieds... & \\
\hline 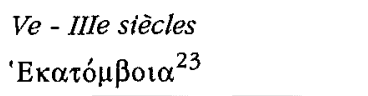 & divers ustensiles en bronze & $\begin{array}{l}\text { Fondation par le Roi } \\
\text { Archinos }\end{array}$ \\
\hline $\begin{array}{l}\text { Basse époque bellénistique } \\
\text { ' } \mathrm{H} \rho \alpha 1 \alpha\end{array}$ & & \\
\hline 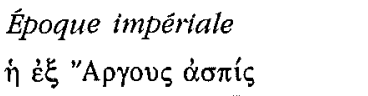 & Bouclier & Bouclier de Danaos \\
\hline
\end{tabular}

L'aition du bouclier de Danaos ne dut pas se figer avant la basse époque hellénistique, longtemps après que l'usage s'était imposé d'offrir un bouclier en prix aux concours d'Héra. Ces concours, comme ceux d'Actium, faisaient partie de la «période » à l'époque impériale ${ }^{24}$.

\section{Le bouclier d'Euphorbe}

Parmi les offrandes qu'il a vués dans le sanctuaire d'Héra, Pausanias signale le bouclier d'Euphorbe suspendu là par Ménélas ${ }^{25}$. Il est muet sur le logos qui lui était associé. L'objet était lié à la légende de Pythagore, connue notamment de Diodore de Sicile ${ }^{26}$ et d'Ovide ${ }^{27}$ : Pythagore prétendait avoir été Euphorbe dans une vie antérieure; il reconnut son bouclier dans le sanctuaire d'Héra. Cette tradition a cependant un doublet attesté dans la littérature philosophique dès le IVe siècle. Pythagore connut plusieurs « pré-incarnations ». Euphorbe s'était d'abord réincarné dans Hermotimos, et c'est ce dernier qui avait reconnu le bouclier d'Euphorbe non pas à Argos, mais dans le sanctuaire d'Apollon à Didymes $^{28}$.

La légende de Pythagore n'a pas été inventée en pays argien. W. Burkert a montré que la tradition qui ne connaissait qu'une seule «préincarnation » de

22 Sur les prix et dans les listes de victoires. Dans les documents officiels, décrets, listes de magistratures, on trouve dès le Ille s., sans doute après le transfert des concours Néméens à Argos,

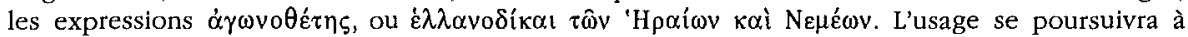
l'époque impériale : par ex. $I G, I V, 590$.

23 C'est la forme connue par les inscriptions : L. MORETTI, Iscr. agon. gr., Rome, 1953, 21, 23, 35, 44. Le décret en l'honneur des Rhodiens, vers 300, donne une autre forme : $\kappa \alpha \rho \hat{v} \xi_{\alpha l} \delta \dot{\varepsilon} \tau o ̀ v$

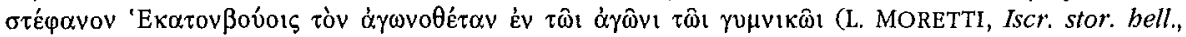

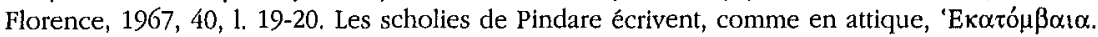

24 Cf. J. et L. ROBERT, Bull. ép., in REG (1954), n 57, p. 114.

25 PAUSANIAS, II, 17, 3.

26 DIODORE DE SICILE, $\mathrm{X}, 6,2-3$.

27 OVIDE, Métamorphoses, XV, 163 : nuper Abantels templo Iunonis in Argis.

28 HÉRACLIDE PONTIQUE, fr. 89 Wehrli (= DIOGÈNE LAËRCE, VII, 4). 
Pythagore avait dû précéder celle qu'ont répandue les philosophes et que, par conséquent, la légende de la reconnaissance du bouclier par Pythagore en personne était la plus ancienne ${ }^{29}$. Mais la scène se passait-elle à Argos, ou dans le sanctuaire des Branchides? Le sanctuaire de Milet était tout près de Samos. Les liens qu'Euphorbe entretenait avec Apollon, bien mis en avant par $\mathrm{P}$. Wathelet ${ }^{30}$, donnent un sens à l'offrande de Ménélas dans le sanctuaire de Didymes $^{31}$. La scène a pu n'être transposée qu'après coup à l'Héraion d'Argos par quelque érudit désireux d'embellir l'histoire du sanctuaire de la déesse ou tout simplement soucieux de vraisemblance : une dépouille troyenne déposée par Ménélas près de Mycènes lui aura paru moins déplacée qu'à Milet ${ }^{32}$.

Dans l'état actuel de nos connaissances, les mythes que nous venons d'évoquer ne nous renvoient à rien de très ancien. Ils ne se rapportent pas non plus à des cultes, sinon indirectement, dans la mesure où les concours font partie des pratiques religieuses. Il ne resterait donc qu'un seul texte dont on pourrait déduire que le culte d'Héra possédait une connotation guerrière ou militaire - le passage d'Énée le Tacticien ${ }^{33}$ faisant allusion à une procession d'hommes en armes -, si J. Labarbe n'avait démontré de manière convaincante qu'il ne pouvait se rapporter qu'à Samos ${ }^{34}$.

En revanche, avec le bouclier de Diomède, nous sommes renvoyés explicitement au culte d'Athéna, grâce à Callimaque et, peut-être, grâce à Homère, ce qui permettrait de remonter très haut dans le temps.

\section{Le bouclier d'Athéna}

La Larisa est une colline conique aux flancs escarpés dont le sommet, à $289 \mathrm{~m}$, est occupé actuellement par la citadelle d'Argos. Elle est séparée par un col situé à $54 \mathrm{~m}$ au-dessus du niveau de la mer d'une deuxième colline dont le

\footnotetext{
29 W. BURKERT, Lore and Science in Anclent Pythagoreanism, Cambridge, MA, 1972, p. 138141.

30 P. WATHELET, Dictionnatre des Troyens de l'tliade, Llège, 1988, 129.

31 Le motif du bouclier n'est pas dans l'Iliade, où Hector, pressé par Apollon, empêche Ménélas de dépouiller Euphorbe (P 61-109). La représentation du combat de Ménélas et d'Hector sur le corps d'Euphorbe qui figure sur un plat rhodien de la fin du VIIe s. (L. KAHIL, LIMC, IV [1988], p. 68, art. Euphorbos, I, 1) pourrait s'inspirer de cette scène. Mais E. SIMON, Griech. Vasen, Munich, 1976,31 , p. 54-55, pense que le peintre a peut-être voulu signifier que les armes iraient à Ménélas. Il est hasardeux de vouloir en tirer un argument en faveur de l'ancienneté du motif du bouclier à Argos, ou ailleurs. - Pour le problème posé par l'écriture, voir L. JEFFERY, The Local Scripts of Archaic Greece, Oxford, $1990^{2}$, p. 153-154, 354).

32 Les Ioniens n'ont cependant pas trouvé incongru de faire passer par chez eux les héros revenant de Troie. Ainsi Pygéla passait pour avoir été fondée par des soldats d'Agamemnon : STRABON, XIV, 1, 20 (C639); THÉOPOMPE, 115 F 59 Jacoby (= HARPOCRATION, s.v. Пú $\gamma \varepsilon \lambda \alpha$ ). $C f$. M.B. SAKELlARIOU, La migration grecque en Ionie, Athènes, 1958, p. 116-118, où l'on trouvera d'autres traditions.
}

33 ÉNÉE LE TACTICIEN, XVII, 2-4.

34 J. LABARBE, Un putsch dans la Grèce antique : Polycrate et ses frères à la conquête du pouvoir, in Ancient Society, 5 (1974), p. 21-41, sp. 23-28. 
sommet, à $80 \mathrm{~m}$, est couronné par une chapelle dédiée au Prophète Élie. À cause de sa forme, qui rappelle un bouclier, Sir William Gell a cru y reconnaître le lieu-dit que Plutarque appelle «Aspis ». Bien que cette dénomination soit fausse, l'habitude de désigner ainsi la colline demeure solidement implantée ${ }^{35}$. Pausanias nous apprend le nom que portait l'endroit dans l'Antiquité : Deiras. On y trouvait le sanctuaire d'Apollon Pythaeus, appelé, à cause de l'endroit où il se trouvait, Deiradiôtès ${ }^{36}$.

Le sanctuaire de Pythaeus possède ses propres récits mythiques que j'ai étudiés ailleurs ${ }^{37}$. Les autres font intervenir Diomède ou des légendes du cycle troyen $^{38}$ :

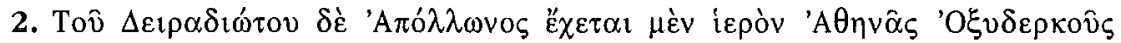

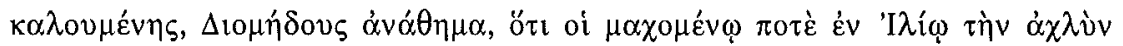
$\dot{\alpha} \varphi \varepsilon \hat{\imath} \lambda \varepsilon v \dot{\eta} \theta \varepsilon \dot{\varsigma} \varsigma \dot{\alpha} \pi$ ò $\tau \hat{\omega} v$ ó $\varphi \theta \alpha \lambda \mu \hat{\omega} v \cdot[\ldots]$

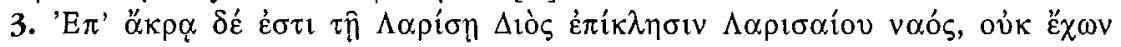

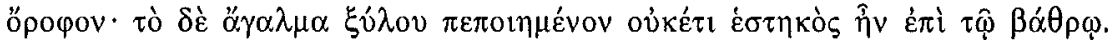

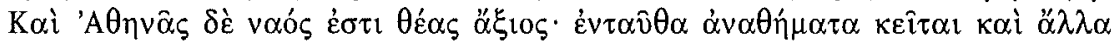

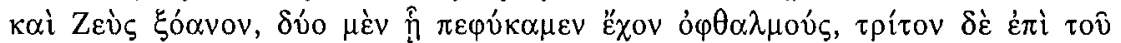

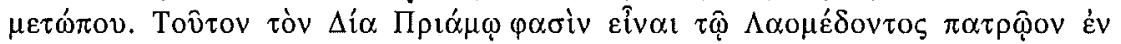

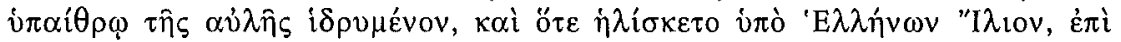

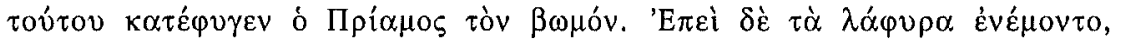

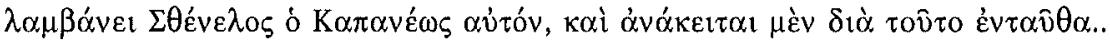

2. Le sanctuaire d'Athéna qu'on appelle Oxyderkès touche à celui d'Apollon Deiradiôtès; il a été dédié à cette déesse par Diomède, parce que dans un combat devant Troie, elle avait écarté de ses yeux le nuage qui les recouvrait [...]

3. Au sommet de la Larisa, il y a un temple de Zeus Larisaios. Il n'a plus de toit. La statue de culte faite en bois n'est plus sur sa base. Il y a aussi un temple d'Athéna qui mérite d'être vu. Parmi les offrandes qui s'y trouvent, il y a un xoanon de Zeus. En plus des deux yeux avec lesquels nous sommes nés, il en a un troisième sur le front. Ce Zeus, dit-on, était la divinité ancestrale de Priam, le fils de Laomédon; sa statue était installée dans la cour du palais. Lors de la prise de Troie par les Grecs, c'est sur son autel que Priam se réfugia. Lors du partage du butin, Sthenelos, fils de Kapaneus, la reçut et c'est la raison pour laquelle il la dédia à cet endroit.

Pausanias s'efforce ensuite d'expliquer pourquoi la statue avait trois yeux.

35 V. LAMBRINOUDAKIS, in AOHNA, 71 (1970), p. 47-80, puis F. CROISSANT, BCH, 96 (1972), p. 144-154, ont démontré avec des arguments décisifs que l'Aspis devait être recherchée sur les flancs mêmes de la Larisa, au-dessus du théâtre.

36 PAUSANIAS, II, 24, 1 - sur le sanctuaire d'Héra, vu par Pausanias sur le chemin de l'Acropole, mais dont nous ne savons rien d'autre, voir mon article sous presse Hadrien et Argos, in Mélanges H. Lieb (1995).

37 M. PIÉRART, Un oracle d'Apollon à Angos, in Kernos, 3 (1990), p. 319-333.

38 PAUSANIAS, II, 24, 2-3. 
Il est vraisemblable que la statue de Zeus exposée dans la sanctuaire d'Athéna était celle qui se trouvait auparavant dans le sanctuaire de Zeus et qu'on l'y a mise pour la préserver après l'effondrement de la toiture. Pausanias en parle encore dans la liste des statues de culte dérobées donnée au livre VIII $^{39}$. Là Zeus est dit Herkeios. C'est, semble-t-il, l'épithète de la tradition homérique, conservée par Euripide, dans les Troyennes:

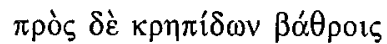

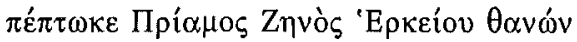

Sur les marches de l'autel de Zeus Herkeios, Priam est tombé mort.

Le scholiaste cite à propos de ces vers les Argolika d'Hagias et Derkylos ${ }^{40}$ :

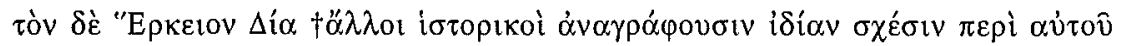

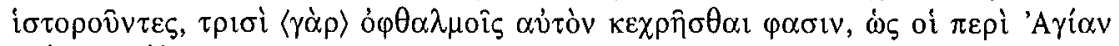

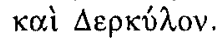

$\grave{A}$ propos de Zeus Herkeios, $\uparrow$ d'autres historiens rapportent dans leurs écrits une disposition particulière : ils disent qu'il faisait usage de trois yeux. Ainsi Hagias et Derkylos.

Si Pausanias ne mentionne pas la statue de culte d'Athéna, ce n'est pas qu'elle ait disparu. Il vient d'en parler, dans sa critique de traditions argiennes ${ }^{41}$ :

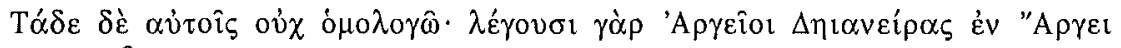

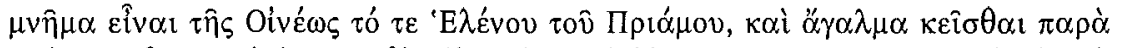

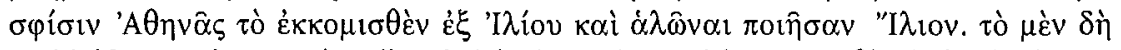

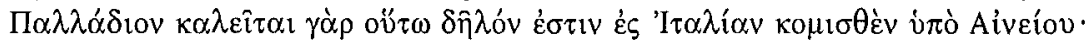

Je suis en désaccord avec eux sur ces points : ils prétendent que se trouve chez eux la tombe de Déjanire, fille Oineus, la tombe d'Hélénos, fils de Priam et la statue d'Athéna ramenée de Troie et dont la possession fut la cause de la prise de la ville. Mais il est évident que le Palladion - c'est ainsi qu'on appelle la statue a été emporté en Italie par Énée...

L'analogie entre le sort de la statue de Zeus et de celle d'Athéna prouve que la statue exposée dans le sanctuaire de la Larisa était pour les Argiens le Palladion ramené de Troie par Diomède. C'est elle qui faisait l'objet du culte

39 PAUSANIAS, VIII, 46, 2.

40 Hagias et Derkylos, 305 F 6 Jacoby (= Schol. ad Eur. Troad., 16 [II, p. 348 Schwartz]). Sur ces auteurs, voir l'étude d'A.C. CASSIO, Storlografia locale di Argo e dorico letterario, in RFIC, 117 (1989), p. 257-275.

41 PaUSANIAS, II, 23, 5. Cf. aussi le passage cité ci-dessous, n. 50. 
décrit dans le poème de Callimaque, si l'on suit l'avis de son scholiaste, qui a puisé dans une histoire d'Argos le récit des exploits d'Eumédès ${ }^{42}$ :

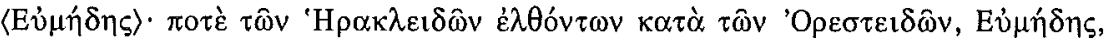

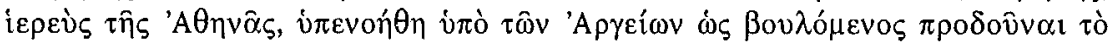

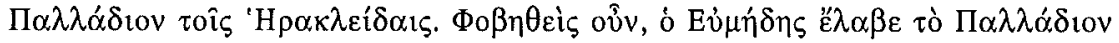

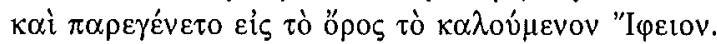

<Eumédès> : jadis quand les Héraclides vinrent combattre les Orestides, Eumédès, prêtre d'Athéna, fut soupçonné par les Argiens d'avoir l'intention de livrer le palladion aux Héraclides. Pris de peur donc, Eumédès prit le Palladion et se rendit dans la montagne appelée Ipheion.

Lors de leur retour, les dynasties royales argiennes étant éteintes, les Héraclides combattirent contre Tisamenos, le fils d'Oreste, qui gouvernait à la fois en Laconie et en Argolide ${ }^{43}$. Eumédès, prêtre de Pallas, protégea le Palladion pour le remettre aux vainqueurs, avec l'agrément de la déesse, qui légitimait ainsi leur entreprise. Instauré par Eumédès - les deux personnages

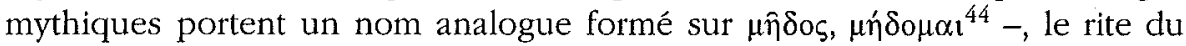
bouclier de Diomède se rattache ainsi à la troisième fondation d'Argos, celle de Témenos.

Pour W. Vollgraff, le sanctuaire d'Athéna Oxyderkès se serait situé sur la terrasse supérieure du sanctuaire d'Apollon Pythéen. Mais G. Roux préférait l'identifier avec la tholos exhumée en contrebas et il est tentant de le suivre sur ce point ${ }^{45}$. Des commentateurs de Callimaque ont placé là le Palladion ${ }^{46}$. Mais cela ne concorde pas avec les indices que nous possédons. Dès le VIe siècle, le

42 Schol. ad Call., $H$., V 37 (II, p. 75 Pfeiffer). - Sur les variantes entre la scholie et le texte, voir K.J. MCKAY, The poet at Play, Leiden, 1962, p. 67-69.

43 PAUSANIAS, II, 18, 5-9.

44 Sur cette formation, $c f$. P. WATHELET, op. cit. (n. 30), 125, (à propos d'Eumédès, père de Dolon).

45 W. VOllgRafF, Le sanctuaire d'Apollon Pythéen à Argos, Paris, 1956, p. 51-55. G. Roux, Le sanctuaire arglen d'Apollon Pytbéen, in REG, 70 (1954), p. 484; L'arcbitecture de l'Argolide aux IVe et IIIe siècles avant J.-C., Paris, 1961, p. 71-72. D'après les observations qu'on peut faire sur le site, le péribole de la tholos est clairement distinct de celui du sanctuaire d'Apollon. Les statuettes d'Athéna trouvées par W. Vollgraff à proximité de la terrasse supérieure pourraient provenir de ce secteur. En revanche, on ne suivra pas G. Roux lorsqu'il propose d'identifier la terrasse supérieure avec un sanctuaire d'Asclépios. L'édifice à citerne pourrait très bien appartenir à Apollon. À Épidaure, les guérisons sont attribuées à Apollon Maléatas et à Asclépios $\left(I G, I^{2} 1,121,1.2\right)$. $C f$. cidessous, fig. 1.

46 U. VON WILAMOWITZ-MOELLENDORFF, Hellen, Dicbtung in der Zelt des Kallimachos,

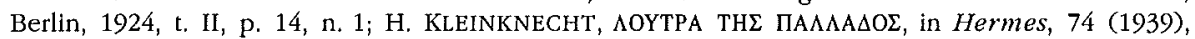
p. 311, n. 2. - Je ne m'attarde pas à l'identification proposée par cet auteur, Palladion = bouclier de Diomède (p. 306-315). Elle a été réfutée par L. ZIEHEN, Das argive Palladium, in Hermes, 76 (1941), p. 426-429; K.J. MCKAY, op. cit. (n. 42), p. 26-28. 
temple d'Athéna sur l'acropole de la Larisa était dédié à Athéna Polias ${ }^{47}$. Il est raisonnable de penser que ce culte et celui de Zeus étaient anciens : dans le cas d'Athéna, au moins, on peut peut-être faire état d'un important dépôt votif. Il s'étend de $\sim 750$ à $~ 650$ environ et paraît appartenir à une divinité féminine, mais on ne peut le mettre en relation avec aucune des structures dégagées ${ }^{48}$. Le temple de l'acropole était le lieu normal où installer le Palladion. Des monnaies d'Argos représentent d'ailleurs le Palladion au sommet d'une colline, mais il serait dangereux d'en tirer argument ${ }^{49}$. Plus important est le fait que Pausanias, décrivant le xoanon d'Athéna dans le temple de Lessa, dit qu'il ne différait en rien de celui qui était sur l'acropole de la Larisa ${ }^{50}$. On donnera donc raison sur ce point à ceux qui mettent le xoanon de la déesse sur la Larisa ${ }^{51}$.

En revanche, rien ne s'oppose à ce que le bouclier de Diomède ait été conservé dans le temple de la Deiras ${ }^{52}$. C'est une pure hypothèse, mais j'imaginerais volontiers que dans la mise en scène très «cinématographique » de l'hymne, les jeunes baigneuses de Pallas attendent la statue à peu près là où sont aujourd'hui les Portitses, à la jonction des deux chemins ${ }^{53}$ : les reliques venues des deux temples se seraient rejointes à la Porte de la Deiras, pour former ensemble le cortège qui partait vers la rivière ${ }^{54}$.

47 SEG, XI, 314; en dernier lieu, H. VAN EFFENTERRE - F, RUZÉ, Nomima, Rome, I, $1994, \mathrm{n}^{\circ} 88$.

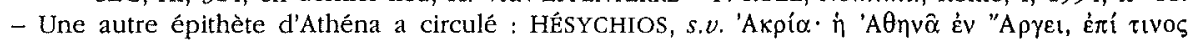

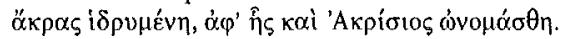

48 W. VOllgrafF, Arx Argorum, in Mnemosyne, 56 (1928) p. 315-328; R. HÄGG, Geometric sanctuaries in the Argolid, in Polydipsion Argos (op. ctt., n. 4), p. 10-11.

49 Cf. L. LACROIX, Les reproductions de statues sur les monnates grecques, Liège, 1949, p. 112116.

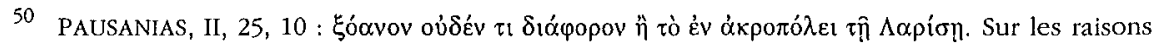
de Pausanias de préférer la variante romaine, voir M. PIÉRART, Les bonneurs de Persée et d'Héraclès, in C. BONNET - C. JOURDAIN-ANNEQUIN (éds), Héraclès, Bruxelles-Rome, 1992, p. 231-232.

51 W. VOLLGRAFF, op. cit. (n. 48), p. 53, après avoir penché pour l'autre solution, a fini par se rallier à cette vue; K. J. MCKAY, op. cit. (n. 42), p. 28; A.W. BULLOCH, Callimachus, The Fifth Hymm, Cambridge, 1985, p. 15.

52 A.W. BULLOCH, op. cit. (n. 51), p. 15-16.

53 Cf. la description de J. DeshAYEs (Les fouilles de la Deiras, Paris, 1966, p. 1) : « Depuis les dernières maisons des faubourgs, la vallée monte très sensiblement jusqu'à un seuil que l'on nomme localement les "Portitses »; au-delà, le paysage s'élargit brusquement et l'on redescend lentement sur la plaine d'Argolide [...]. » De nos jours, pour se rendre commodément à l'Acropole,

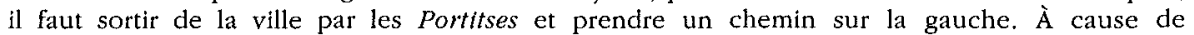
l'escarpement de la colline du côté de la ville, il devait en être de même autrefois. On voit mal par où un char aurait pu monter ou descendre de la Larisa à l'intérieur des murs. C'est d'ailleurs un détour de ce genre que suggère l'itinéraire suivi par Pausanias.

54 La formulation du vers 35 pourrait impliquer que la statue et le bouclier sont séparés à un moment donné. Le trajet n'est pas reconstituable. On a douté que le fleuve soit l'Inachos, à cause de la distance : F. BÖMER, art. Pompa, in RE, XXI 2 (1952), c. 1927-1928, n. 64. Mais Callimaque, $H$., $\mathrm{V}, 49-51$, ne permet pas d'hésiter. Le point le plus proche où baigner la statue est l'endroit où Pausanias franchit la tivière en venant de l'Héraion : $c f$. M. PIÉRART, Deux notes sur l'itinéraire arglen de Pausanias, in BCH, 106 (1982), p. 140-146. Dans ce cas, le cortège devait traverser la ville pour se rendre au bord de l'Inachos par la porte d'Ilythie. 
A.W. Bulloch, dans son commentaire de l'Hymne V, animé du souci légitime de défendre la cohérence du poème contre Wilamowitz et quelques autres qui, gênés par l'aition d'Eumédès, imaginaient une lacune dans le texte, a supposé que Diomède était intervenu pour protéger le prêtre et la statue dans leur exil dans la montagne, soit en apparaissant en personne, soit grâce au pouvoir de son bouclier. «Les garanties renouvelées envers Athéna sont donc essentielles, dit-il, le Bouclier représentant sans doute la protection du Palladion quand il s'éloigne de son temple, comme autrefois, dans ces moments critiques où les Héraclides réclamaient leur part ${ }^{55}$, » Je ne dis pas que cela est faux, mais il me paraît dangereux de fonder une interprétation sur un mythe qu'on a soimême reconstruit de toutes pièces. Heureusement, Diomède n'est pas un inconnu...

Diomède, le fils de Tydée - lui-même fils d'Oineus d'Étolie -, introduit dans la généalogie d'Argos grâce à son mariage avec Déipylè, la fille d'Adraste, est un héros célèbre en Grèce ${ }^{56}$. Il occupe une place importante dans le cycle troyen, où l'on peut voir qu'il entretient des relations étroites avec Athéna ${ }^{57}$. Elles éclatent au chant V de l'Iliade.

Diomède y combat avec fureur aux côtés de Sthenelos, le fils de Kapaneus, qu'on vient de retrouver sur la Larisa, à propos de la statue de Zeus. Blessé à l'épaule par l'archer Pandore (qui ne perd d'ailleurs rien pour attendre), il implore Athéna de le secourir. Celle-ci entend sa prière ${ }^{58}$ :

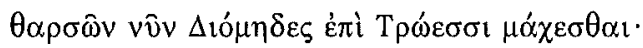

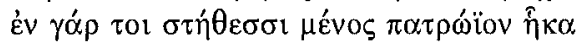

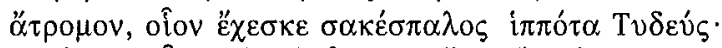

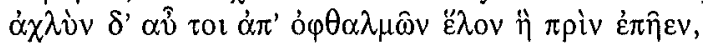

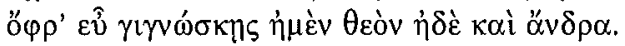

Maintenant combats sans crainte les Troyens, Diomède; je mets en ta poitrine la fougue de ton père, cette fougue intrépide qu'en brandissant son bouclier montrait Tydée, le bon meneur de char. J'écarte aussi de tes yeux le nuage qui jusqu'ici les recouvrait. Tu sauras de la sorte distinguer un dieu d'un homme.

Elle lui conseille alors de ne pas se frotter aux Immortels, à l'exception d'Aphrodite, et se retire du combat. Au cours des combats qui suivent, Diomède blesse Aphrodite et, toujours en fureur, s'attaque à Apollon qui protège Énée. Apollon le repousse. Arès entre en lice et, se remémorant les

55 A.W. BULloCH, op, cit. (n. 51), p, 146-147; l'extrait traduit est à la p. 147. Cf. U. vON WILAMOWITZ-MOELLENDORFF, Hellen. Dicbtung, t. II, p. 17-18.

56 Il est superflu de citer ici les dictionnaires de mythologie : cf. J. BOARDMAN - C.E. VAFOPOULOU-RICHARDSON, art. Diomedes I, in LIMC, III 1 (1986), p. 396-409.

57 Cf. $\varnothing$. ANDERSEN, Die Diomedesgestalt in der Ilias, Oslo etc., 1978. - Sur Athéna et Diomède, voir aussi P. WATHELET, Atbéna cbez Homère, in Kernos, 8 (1995), p. 167-185.

58

HOMÈRE, E 124-128. 
mots de la déesse, Diomède recule. Irritées par le carnage d'Achéens dont Arès se rend coupable, Athéna et Héra obtiennent de Zeus la permission d'intervenir. Athéna, en grande tenue de combat, vient trouver Diomède et lui promet qu'avec son aide il combattra même Arès. Elle fait descendre Sthenelos du char de Diomède et monte à sa place. Grâce à l'aide de la déesse, Diomède blesse Arès, qui se réfugie auprès de Zeus. Les déesses se retirent.

Les points de contact entre le récit homérique et les données argiennes sont trop nombreux pour relever du hasard. Il n'y a pas mille façons de les expliquer.

Une première hypothèse consiste à penser à une influence directe de l'Iliade sur les mythes et les rites argiens. Elle ne peut être écartée a priori. Une telle hypothèse rendrait compte de deux aspects de la légende : l'identification du xoanon d'Athéna Polias avec le Palladion troyen et le rite du bouclier, si l'on admet que ce dernier symbolisait le héros qu'Athéna protège en n'hésitant pas à combattre à ses côtés. Mais il resterait à expliquer le reste du rituel et à comprendre pourquoi le mythe évoqué par Callimaque attribuait la création du rite du bouclier à l'époque du retour des Héraclides. De plus, l'épiclèse d'Athéna Oxyderkès, qui n'est connue, hors d'Argos, qu'à Épidaure ${ }^{59}$, n'est pas dans l'Iliade. Si Tydée y est appelé $\sigma \alpha \kappa \varepsilon ́ \sigma \pi \alpha \lambda o \varsigma$, une épithète qui était déjà obscure pour les anciens ${ }^{60}$, Diomède n'y est pas distingué spécialement par son bouclier ${ }^{61}$. Une influence directe de l'lliade sur le culte argien est donc très peu probable.

Une deuxième hypothèse reviendrait à penser à une influence directe d'Argos sur les récits homériques. Elle a été faite récemment par L.S. Klein, dans un article intitulé The Danaian Iliad ${ }^{62}$. L'auteur entend démontrer que l'Iliade est faite de deux parties, qui se distinguent l'une de l'autre par des particularités lexicales et de contenu : une Achilléide et une Danaïde. Celle-ci occuperait les chants V, IX, XI, XV, XVII et une partie du chant VI. Elle se caractériserait par la place faite à Diomède : le roi d'Argos et Achille s'excluent mutuellement dans le poème d'Homère. La Danaïde aurait été composée à Argos, du temps de

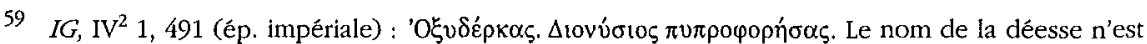
pas mentionné dans l'inscription. - Les commentateurs ont fait divers rapprochements

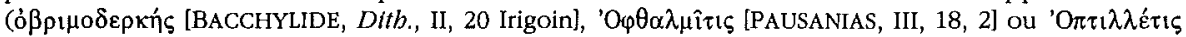
[PLUTARQUE, Lycurgue, 11, 8].

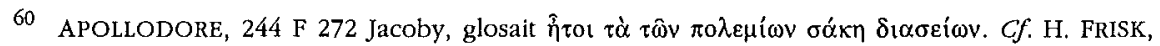

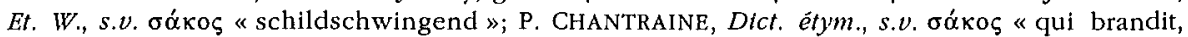
manie un bouclier».

61 En E 8, il est vrai, Athéna fit jaillir un feu infatigable de son casque et de son bouclier ( $\delta \alpha i \imath_{\varepsilon}$

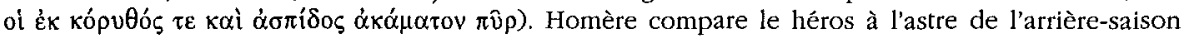
à son lever. - Un fragment de Timée ( $566 \mathrm{~F} 53$ Jacoby) rapporte que Diomède, après avoir quitté Argos, a combattu un dragon grâce au bouclier d'or de Glaukos ( $\kappa \alpha \tau \in ́ \chi \omega \nu)$.

62 L.S. KLEIN, The Danaian Iliad [en russe], in VDI (1990), 1, p. 22-53. - Je remercie Askold Ivantchik de m'avoir facilité l'accès à cet article. 

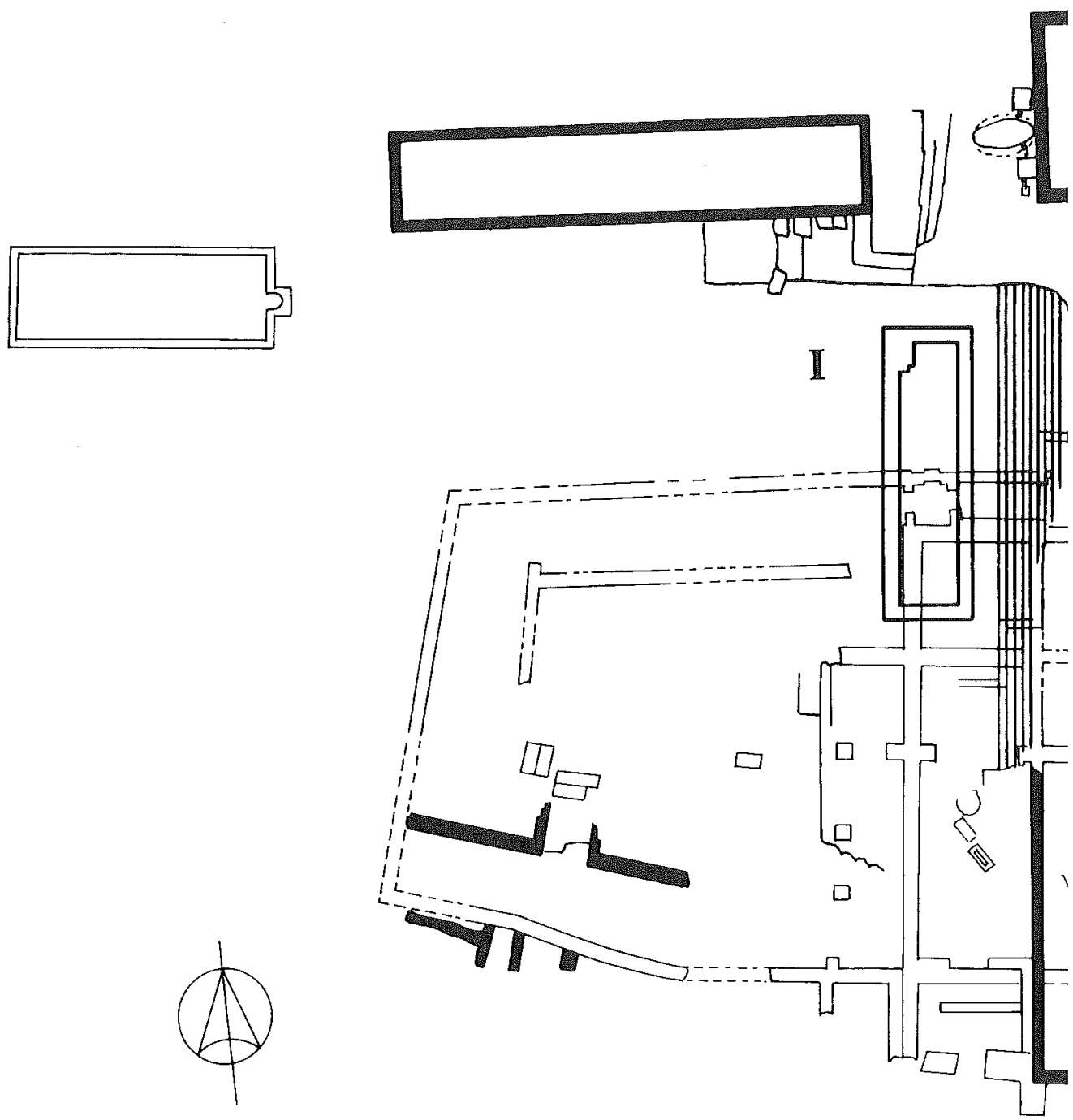

Fig. 1: Les sanctuaires de la Deiras (relevé EFA). - Les traits pleins représentent les structures classiques : I. Autel et gradins droits du sanctuaire d'Apollon. II. Emplacement présumé du sanctuaire d'Athéna pour W. Vollgraff. III. Édifice à tholos identifié par G. Roux avec le temple d'Athéna Oxyderkès. 

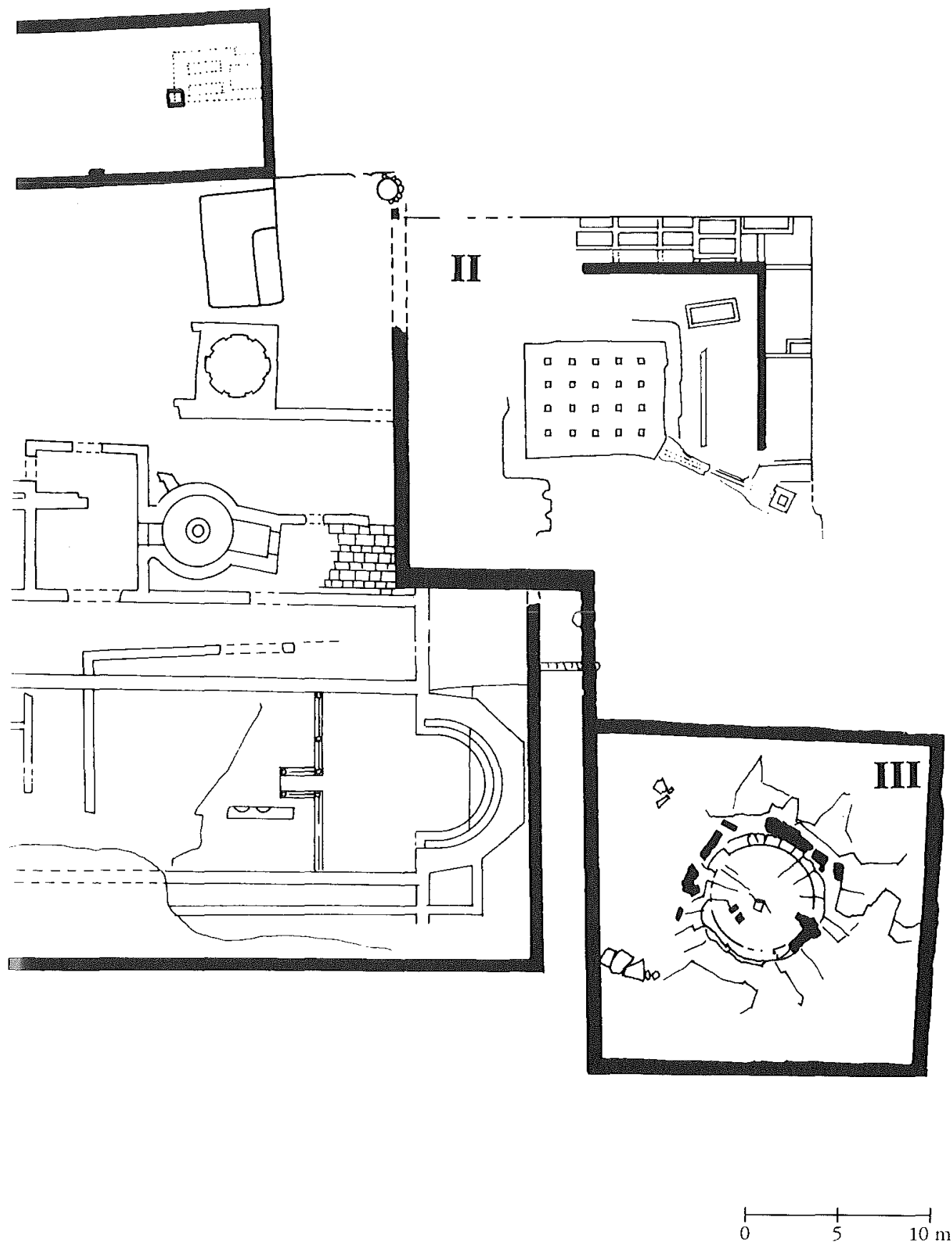
Pheidon, dans le deuxième quart du VIIe siècle L'hypothèse résiste difficilement à l'examen. Si l'Iliade, qu'il est difficile de descendre aussi bas que le VIIe siècle, avait été composée partiellement à Argos, on s'attendrait à trouver des traces de la langue que l'on y parlait. L'étude de la langue homérique invite à penser le contraire. Tout plaide d'ailleurs en faveur d'un isolement relatif d'Argos à haute époque. Le rôle des Danaens dans l'Iliade s'explique mieux par la longue histoire de la tradition épique ${ }^{63}$. Il faut ranger décidément l'idée d'une Iliade argienne, même petite, dans le placard des idées saugrenues.

Mais il est sans doute possible de sortir de ce dilemme aux termes trop tranchés. Les récits de l'Iliade paraissent receler des mythes plus anciens ayant pour thème la protection de Tydée et de Diomède par Athéna. Ce dernier y apparaît comme un héros en quête d'immortalité. L'épisode de l'échange de ses armes contre celles de Glaukos ${ }^{64}$ et la Dolonie ${ }^{65}$ ont été interprétés dans ce sens. En recevant d'Athéna au chant $\mathrm{V}$ le don de reconnaitre les dieux des hommes, Diomède n'accède-t-il pas à une forme d'immortalité ?

Pindare, dans l'ode pour 'Théaios d'Argos, rappelle qu'Athéna fit cadeau au héros de l'immortalité ${ }^{66}$. Ibycos l'avait peut-être déjà dit avant lui ${ }^{67}$. La scholie qui nous l'apprend donne quelques détails à ce sujet ${ }^{68}$ :

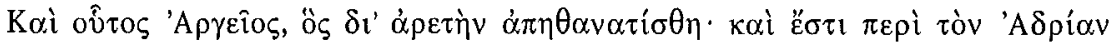

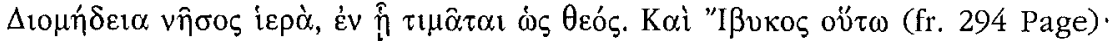

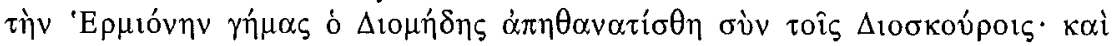

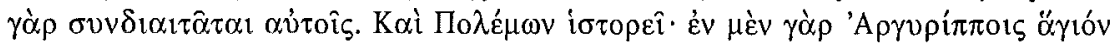

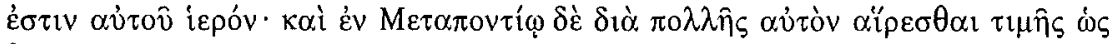

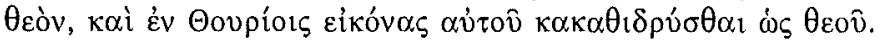

Il s'agit de Diomède l'Argien, immortalisé à cause de son excellence. Il y a dans l'Adriatique une île sacrée appelée Diomédeia, dans laquelle il est honoré comme un dieu. Ibycos raconte que Diomède, après avoir épousé Hermione, fut immortalisé avec les Dioscures : en effet il partage leur vie. Polémon raconte (FHG III 122 Muller) qu’à Argurippa, un sanctuaire lui est consacré; à Métaponte, il reçoit de grands honneurs comme un dieu et à Thurii, on lui a érigé des portraits comme à un dieu.

Il s'agit là, bien sûr, pour la plupart, de traditions qui avaient cours dans des cités d'Italie, où Diomède a joué un rôle important comme fondateur ${ }^{69}$. Mais

63 Cf. M. PIÉRART, Aspects de la transition en Argolide, in D. MUSTI (éd.), La transizione dal Miceneo all'Alto Arcaismo. Dal palazzo alla città, Rome, 1991, p. 133-144.

64 G. PICCALUGA, Il dialogo tra Diomedes e Glaukos, in SSR, 4 (1980), p. 237-258.

65 P. WATHELET, Rbésos ou la quête de l'immortalité, in Kernos, 2 (1989), p. 213-231.

66 PINDARE, Ném., X, 12-13. Le texte est cité ci-dessus, p. 171.

67 IBYCOS, fr. 294 Page.

68 Schol. ad Pind., Ném., X 12 a (III p. 167-168 Drachmann).

69 Cf. STRABON, VI, 3, 9 (C284). 
elles peuvent s'inspirer de traditions répandues sur le continent grec. La déesse n'avait-elle pas voulu déjà rendre Tydée immortel ? Elle avait renoncé à son dessein au dernier moment parce qu'elle l'avait surpris en train de dévorer la cervelle de l'ennemi qu'il venait d'abattre. Tydée demanda alors à la déesse d'accorder l'immortalité à son fils ${ }^{70}$. L'histoire paraît provenir du Cycle thébain ${ }^{71}$. On ne perdra pas de vue que la Thébaïde fut aussi lue à Argos que l'Iliade, sinon davantage ${ }^{72}$. Il n'est donc pas absurde de penser que cette tradition, évoquée par Pindare devant un auditoire argien, avait aussi cours à Argos même.

$\hat{A}$ travers ces récits se dessine une opposition entre deux types de guerriers, le sanguinaire aveuglé par la colère et perdant tout sens de la mesure, dont Arès est souvent le paradigme dans l'Iliade ${ }^{73}$, et le guerrier vaillant et lucide que protège Athéna. Les mythes dont l'Iliade se faisait l'écho ont pu connaître un certain succès dans des régions avec lesquelles les aèdes homériques n'étaient pas tout à fait sans contact et où ils ont pu d'ailleurs être liés à des rituels ressemblant à celui dont Argos nous a conservé le souvenir.

Si l'on fait abstraction du rite du bouclier, Diomède est, à notre connaissance, absent des cultes argiens. Il ne s'insère qu'indirectement dans la généalogie des rois d'Argos ${ }^{74}$. Il n'a ni tombe hérö̈que, ni sanctuaire dans la cité. Les récits mythiques liés au rituel du bain de Pallas ont donc pu être réinterprétés à Argos même à la lumière de la tradition homérique ${ }^{75}$. Si le Palladion de la Larisa était identifié avec celui de Troie, il a bien fallu, en effet, que les récits locaux relatifs au sanctuaire de la Deiras et de la Larisa aient à un moment ou l'autre été mis en relation avec le Cycle troyen. On conclura donc à une influence des traditions homériques non sur les rites eux-mêmes, qui doivent avoir leur origine propre, mais sur les récits qui les expliquaient et qui, lorsque les poèmes homériques se sont répandus, ont été revus à leur lumière. Cette réinterprétation était antérieure à Pindare, si l'ode pour Theaios d'Argos reflète

70 PHÉRÉCYDE, 3 F 97 Jacoby. Cf. Schol. ad Hom., E 126 (II, p. 22 Erbse).

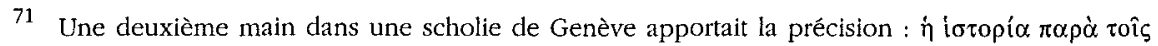

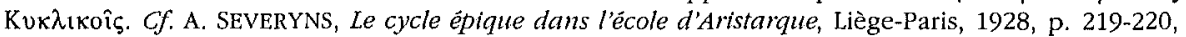
qui traduit ainsi le passage : "Amphiaraos ayant tué Mélanippos, donna la tête à Tydée, qui, tel une brute, la brisa et en huma la cervelle avec frénésie. À ce moment survint Athéna qui, du ciel, lui apportait l'immortalité ( $\alpha \theta \alpha v \alpha \sigma i \alpha v)$. D'horreur elle se détourna. Et lui, voyant cela, demanda que

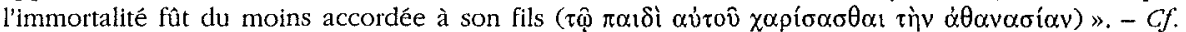

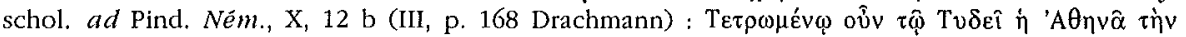

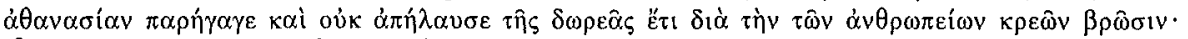

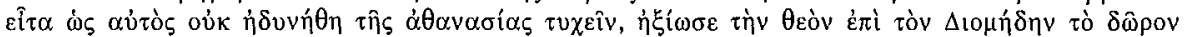

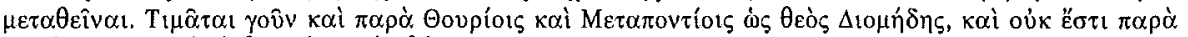

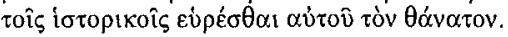

72 Cf. M. PIÉRART (éd.), Polydipsion Argos (op. ctt., n. 4), passim.

73 p. WATHELET, Arès chez Homère ou le dieu mal-aimé, in LEC, 60 (1992), p. 113-128, sp. p. $126-128$.

74 Cf. l'article annoncé ci-dessus, n. 4.

75 Le mot $\alpha \chi \lambda \hat{u} \varsigma$ dans le texte de Pausanias est sûrement une réminiscence d'Homère, mais on ne peut en tirer argument, car le Périégète connaissait son Homère ! 
bien les traditions qui avaient cours dans la cité où elle fut chantée. Elle était probablement beaucoup plus ancienne.

Le bain de Pallas, qui s'inscrit dans un ensemble de rituels très répandus, avait sans doute pour rôle de restaurer sa puissance ${ }^{76}$. C'était l'occasion de demander à la divinité guerrière protectrice d'Argos de renouveler son alliance avec la cité, symbolisée dans les récits mettant en scène Diomède, le roi d'Argos vainqueur de Troie, ainsi que par le rite du bouclier. Celui-ci rappelait, à travers le mythe d'Eumédès, que la déesse n'avait pas hésité à accorder sa protection bienveillante aux Héraclides, qui venaient reprendre possession de leur patrimoine légitime, ainsi qu'aux Doriens qui l'accompagnaient.

Une exégèse complète des mythes et des rites impliqués par l'Hymne $\mathrm{V}$ nous entraînerait très loin et ce n'est pas mon propos. Mais il est deux points dont on ne peut éluder l'examen.

Des commentateurs ont supposé que la statue de la déesse était accompagnée en cortège par des éphèbes ${ }^{77}$. On est même allé jusqu'à attribuer à Athéna la procession d'hommes en armes qu'Énée le Tacticien rapporte à Héra $^{78}$. Athènes connaissait deux bains d'Athéna : celui de la divinité poliade lors des Plyntéria et le bain du Palladion au Phalère, où les éphèbes menaient la déesse en cortège à la mer. On les a longtemps confondus. Mais ils constituaient, comme l'a bien montré W. Burkert, deux cérémonies distinctes ${ }^{79}$. On admettra, toujours à la suite de W. Burkert, que le bain annuel de la déesse argienne est le pendant argien non de la procession du Phalère, mais des Plyntéria à Athènes ${ }^{80}$. Dans les deux cas, le rite s'inscrit dans un processus de dissolution/renouveau : jour néfaste à Athènes, frappé d'interdits à Argos (ne pas boire au fleuve !). Ceci conduit à revoir la validité de l'hypothèse de la participation éventuelle d'éphèbes à la procession d'Argos.

À l'appui de la participation de jeunes gens, on invoque les explications

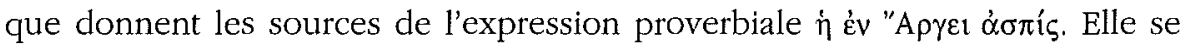
réfère à une coutume ancienne, selon laquelle de jeunes garçons impubères avaient le privilège de porter un bouclier doré dans les processions. Mais on ne nous dit pas dans quelles fêtes ni pour quelle divinité. Nous en possédons deux versions qui diffèrent entre elles: celle de Zenobius, transmise aussi par d'autres parœmiographes, et celle de Plutarque :

76 Cf. L. KAHIL, Bains de statues et de divinités, in R. GINOUVÈs et al. (éd.), L'eau, la santê et la maladie dans le monde grec, BCH Suppl. XXVIII 1994, p. 221-222.

77 F. BÖMER, art. Pompa, in RE, XXI 2 (1952), col. 1927-1928, « eine Vermutung über die Epheben bei Wilamowitz », citant U. von Wilamowitz-Moellendorff, Sitz. Ak. Berlin, 1921, p. 951, n. 4: «Als Schildträger in Prozession zu gehen war eine Auszeichnung für die Jugend »; ID., Hellen. Dichtung, t. II, p. 18 n. 3, parle « von schildtragenden Jünglingen ».

78 F. BÖMER, ibid.

79 W. BURKERT, Buzyge und Palladion, in ZRGG, 22 (1970), p. 356-368. Cf. P. BRULÉ, La fille d'Atbènes, Paris-Besançon, 1987, p. 105-110.

80 W. BURKERT, Griech. Religion, Stuttgart etc., 1977, p. 134-135 (= tr. angl., Harvard 1985, p. 79). 
A. Zénobius, II 3, I p. 32 von Leutsch-Schneiderin.

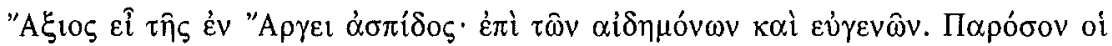

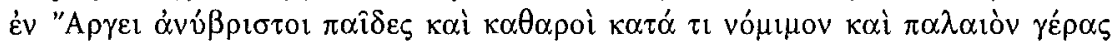

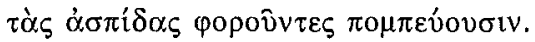

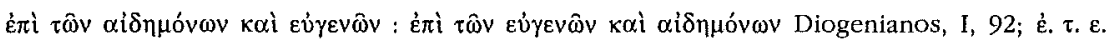

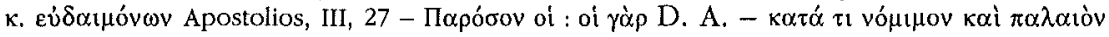

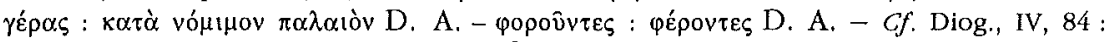

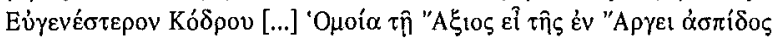

Tu es digne du bouclier d'Argos : <se dit> de personnes modestes et bien nées; parce qu'à Argos, les enfants intacts et purs, par le privilège de quelque ancienne coutume, suivent les processions en portant des boucliers.

B. Plutarque, I 44, p. 327 von Leutsch-Schneiderin.

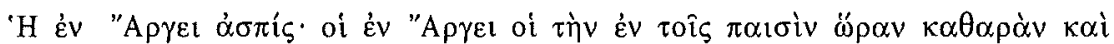

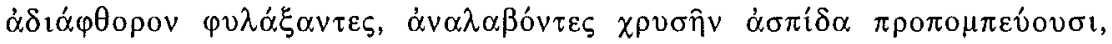

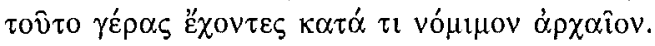

Le bouclier d'Argos : À Argos, ceux parmi les enfants qui préservent leur fraîcheur pure et chaste portent un bouclier d'or en tête de la procession; ils doivent ce privilège à quelque ancienne coutume.

La version $\mathbf{A}$, qui est la plus répandue, parle de boucliers au pluriel et l'on pourrait penser à un cérémonial, qui ne serait pas déplacé à l'époque impériale ${ }^{81}$, où les jeunes garçons portaient en procession les prix du concours d'Héra au début des concours. Mais, comme on l'a vu plus haut, le bouclier n'était, à l'origine, qu'un prix parmi d'autres et l'on s'expliquerait mal, dans ces conditions, que la coutume soit présentée comme très ancienne. La version $\mathbf{B}$ pourrait conduire à une autre interprétation. Elle mentionne un bouclier au singulier, qui est présenté comme un bouclier d'or (comme celui que Glaukos avait donné à Diomède). Elle ne permet donc pas d'exclure l'hypothèse que ces enfants portaient un bouclier unique, ce qui nous ramènerait à la procession d'Athéna.

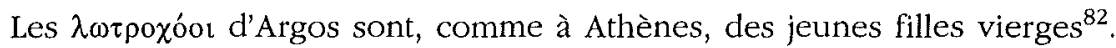
L'insertion par Callimaque du mythe de Tirésias dans l'Hymne $V$ ne se comprend que si les hommes étaient exclus de la cérémonie. Des éphèbes devaient donc l'être également. Mais les explications du proverbe ne laissent planer aucun doute sur le fait que les garçons qui reçoivent le privilège de porter le bouclier sont encore des enfants et qu'ils doivent satisfaire à des exigences de pureté. Ils pourraient, eux, avoir été admis dans le cortège de la déesse. Nous savons en effet par Pausanias que le prêtre d'Athéna Kranaia à Élatée était un jeune garçon qui n'avait pas encore atteint l'âge de l'éphébie. 
On s'arrangeait pour qu'il quitte la prêtrise avant ${ }^{83}$. À Tégée, toujours du temps de Pausanias, le prêtre était de même un jeune garçon ${ }^{84}$. La présence de jeunes garçons dans une procession dont on exclut les adultes mâles ne serait donc pas absurde. Il n'est pas possible d'atteindre à une certitude, puisque la procession n'est pas nommée par les parcmiographes, qui ne paraissent d'ailleurs plus très bien savoir à quoi exactement le proverbe se rapportait, mais on admettra que l'expression «tu es digne du bouclier d'Argos » prendrait tout son sens dans le contexte du bain de Pallas.

On s'attend à ce qu'après son bain dans le fleuve Inachos, la statue de la déesse ait été revêtue de nouveaux habits. Aussi a-t-on rapproché de la cérémonie une notice lexicographique ${ }^{85}$ :

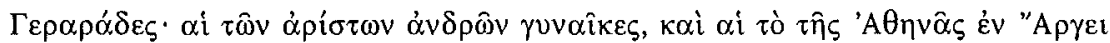
$\not ̈ \gamma \alpha \lambda \mu \alpha \dot{\varepsilon} v \delta \dot{o v} \sigma \alpha \mathbf{t}$.

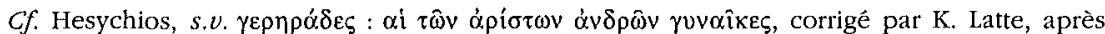
d'autres, en $\gamma \varepsilon \rho \alpha \rho \alpha ́ \delta \varepsilon \varsigma$. Mais M. Schmidt observait : corrige igitur $\gamma \varepsilon \rho \alpha \rho \alpha ́ \delta \varepsilon \varsigma$, quamquam

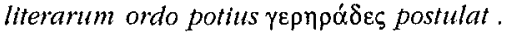

Que la scholie mentionne «les femmes des citoyens d'Argos les plus en vue » n'est peut-être pas un obstacle suffisant pour renoncer à les identifier aux $\lambda \omega \tau \rho \circ \chi$ óor de Callimaque, décrites par le poète comme des $\pi \alpha \rho \theta \varepsilon v ı$ «

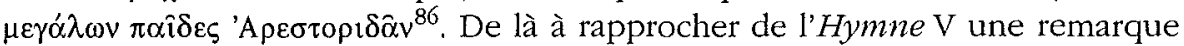
provenant des Moralia, il n'y a qu'un pas ${ }^{87}$ :

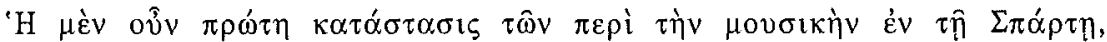

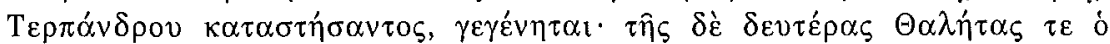

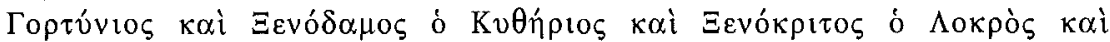

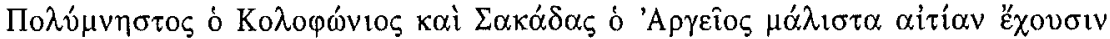

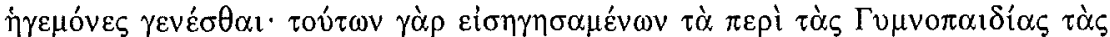

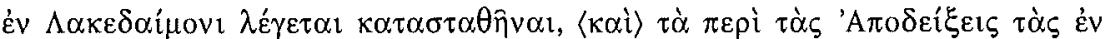

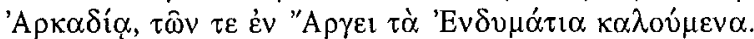

La musique fut instituée en premier lieu à Sparte sous la direction de Terpandre. Les principaux responsables de la seconde organisation sont, dit-on, Thaletas de Gortyne, Xénodamos de Cythère, Xénocritos de Locres, Polymnestos de Colophon et Sakadas d'Argos. En effet, c'est sous leur impulsion que furent

83 PAUSANIAS, $\mathrm{X}, 34,8$.

84 PAUSANIAS, VIII, 47, 3. Cf. M. JOST, Sanctualres et cultes d'Arcadie, Paris, 1985, p. 381, qui pense la coutume récente.

85 An. Gr., I, p. 231, 30 Bekker.

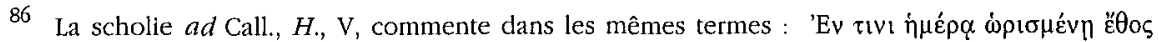

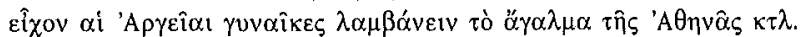

87 [PLUTARQUE], Sur la musique, 9 (Moralia, 1134b-c). 
organisées les fêtes des Gymnopédies à Sparte, des Apodeixeis en Arcadie et des Endymatia à Argos.

On en a donc conclu que les $\Gamma \varepsilon \rho \alpha p \alpha ́ \delta \varepsilon \varsigma$ officiaient dans le cadre de la fête décrite par Callimaque et que celle-ci avait pour nom Endymatid ${ }^{88}$. La tentative est séduisante et n'est sûrement pas à exclure. Mais le poème de Callimaque ne contient rien qui puisse appuyer cette identification. De plus, le rôle attribué dans la fondation de la fête à Sakadas, poète et musicien dont on montrait encore la tombe à Argos à l'époque de Pausanias ${ }^{89}$, qui avait composé de la poésie mélique et élégiaque et passait pour un excellent flûtiste, implique une prestation musicale dont nous n'entendons pas parler dans l'Hymne V. D'autres sanctuaires d'Athéna sont attestés en ville et dans la chôra argienne. Il y avait en ville, non loin de l'agora, un temple d'Athéna «Salpinx ». Une inscription inédite du dernier tiers du IVe siècle, trouvée non loin de l'agora, contient deux textes : (1) un jugement des Quatre-Vingts sur un différend ayant opposé un prêtre de Pallas avec un entrepreneur au sujet de rétributions; (2) une loi sacrée, d'interprétation difficile, qui paraît concerner l'administration de biens appartenant à la déesse ${ }^{90}$. Pausanias mentionnait encore une statue d'Athéna Pania, dans le gymnase de Kylarabis, près de la tombe de Sthenelos ${ }^{91}$. Enfin nous ne pouvons pas exclure que les Endymatia aient concerné une autre déesse. La prudence affichée par Nilsson ${ }^{92}$ reste de règle.

Le mythe relatif à Athéna Salpinx est, comme celui du bouclier, l'un des rares à impliquer les Doriens ${ }^{93}$ :

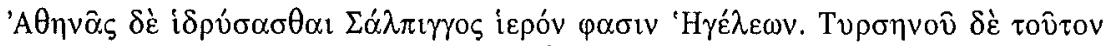

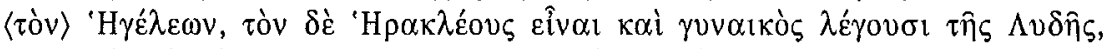

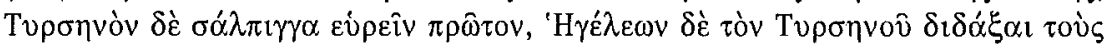

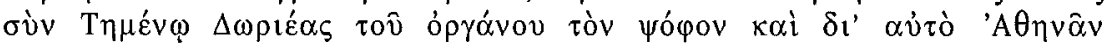

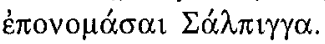

On dit que le sanctuaire d'Athéna Salpinx a été fondé par Hégeleôs. Cet Hégeleôs était, dit-on, le fils de Tyrsénos, le fils d'Héraclès et de sa femme de Lydie. Tyrsénos fut l'inventeur de la trompette. Hégeleôs, fils de Tyrsénos, enseigna le son de cet instrument aux Doriens qui accompagnaient Témenos. C'est pourquoi Athéna fut surnommée Salpinx.

88 U. VON WILAMOWITZ-MOELLENDORFF, Sitz. Ak. Bertin, 1921, p. 951; Hell. Dichtung, II, p. 18 n. 3; F. BÖME, RE, art. Pompa, col. 1927.

89 PAUSANIAS, II, 22, 8.

90 Inv. E 67. Gf. M. PIÉraRT, $B C H 106$ (1982), p. 127, n. 22; 107 (1983), p. 272, n. 23; P. CHARNEUX, $B C H, 107$ (1983), p. 264. L'inscription contenait encore un troisième texte, à peu près effacé.

91 PAUSANIAS, II, 22, 9.

92 M.P. NILSSON, Griechiscbe Feste, Leipzig, 1906, p. 371.

93 PAUSANIAS, II, 21, 3. - Je reviens ailleurs sur la question de la localisation du temple. 
Les commentateurs ont noté que l'explication de Pausanias était elliptique : des scholies et des notices lexicographiques contiennent les débris d'une tradition selon laquelle la trompette était une invention d'Athéna en personne ${ }^{94}$ :

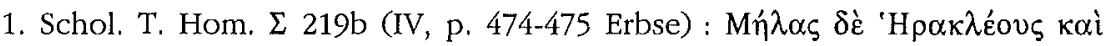

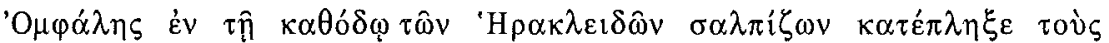

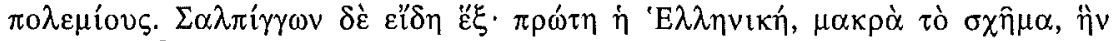

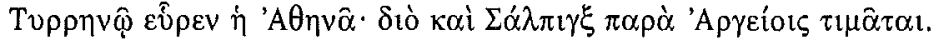

Mélas, fils d'Héraclès et d'Omphale; lors du retour des Héraclides, il épouvanta les ennemis en jouant de la trompette. Il y a six sortes de trompettes. La première, la trompette grecque, de forme longue, qu'Athéna a inventée pour Tyrrhénos. C'est pourquoi elle est honorée chez les Argiens du nom de Salpinx.

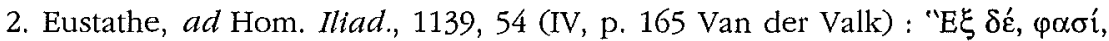

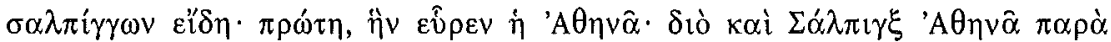

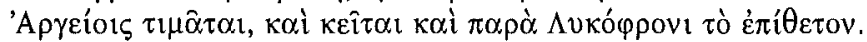

Il y a, dit-on, six formes de trompettes. La première est une invention d'Athéna. C'est pourquoi elle est honorée <sous le nom de> Salpinx chez les Argiens. L'épithète se trouve aussi chez Lycophron (Alexandra, 915, 986).

3. Schol. Eur., Pbén. 1377 (I, p. 388, 25 Schwartz) [= schol. Soph., Ajax, 17 (p. 3

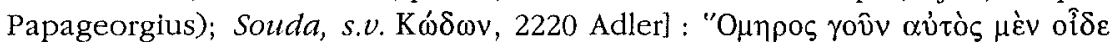

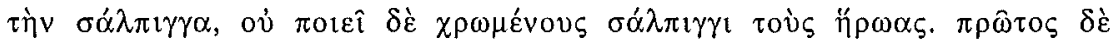

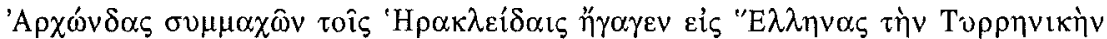
$\sigma \alpha \dot{\lambda} \lambda \iota \gamma \gamma \gamma \alpha$.

Homère connaissait personnellement la trompette, mais ses héros ne l'utilisent pas dans ses poèmes. Archondas le premier, en combattant aux côtés des Héraclides, introduisit chez les Grecs la trompette tyrrhénienne.

4. Et. Magnum, 708, 2 Gaisford (= schol. Tzetzes ad Lyc., Al., 915 [II, p. 295

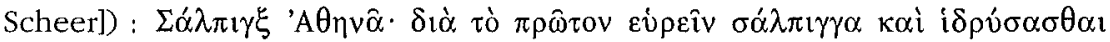

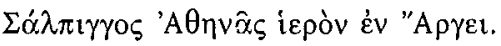

Salpinx Athéna. Parce qu'elle inventa la trompette; un sanctuaire d'Athéna Salpinx fut fondé à Argos.

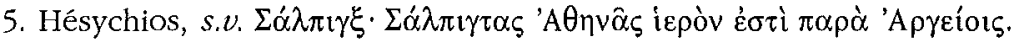

En dépit de variantes portant sur les noms des personnages impliqués dans l'histoire, ces textes rattachent l'invention de la trompette à Athéna, et son introduction en Grèce à l'épisode du retour des Héraclides. L'épithète Salpinx n'est d'ailleurs connue qu'à Argos. C'est là sans doute que Lycophron l'a trouvée.

La trompette était utilisée à des fins militaires. Son association avec Athéna, d'une part, les Doriens, de l'autre, était naturelle. Les scholies citées ci-dessus

94 Pour l'ensemble de la tradition, extrêmement complexe, voir D. BRIQUEL, L'origine lydienne des Étrusques, Rome, 1991, p. 319-344. 
inscrivent d'ailleurs son introduction dans ce contexte : les Doriens épouvantaient leurs ennemis au son de la trompette.

Les récits qui ont eu la préférence des Argiens, lorsqu'ils tentaient d'expliquer les cultes qu'ils vouaient à Athéna, se rattachent de préférence au cycle troyen et à la légende du Retour des Héraclides ${ }^{95}$. L'examen des cultes de Zeus montrerait une tendance sembable ${ }^{96}$. Un simple coup d'œil au tableau suivant, qui regroupe les cultes connus de Pausanias, en convaincra aisément le lecteur :

\begin{tabular}{|c|c|c|}
\hline II, 19,8 & Zeùs 'Yétios & Lieu du serment des héros de Thèbes \\
\hline II, $20,1-2$ & 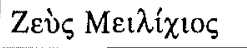 & Guerre civile de 416 \\
\hline II, 20,3 & 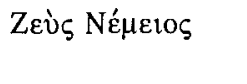 & $\begin{array}{l}\text { La fondation des concours est liée au Cycle } \\
\text { thébain }\end{array}$ \\
\hline II, 20,6 & Zzùs $\Sigma \omega \tau n ́ \rho$ & \\
\hline II, 21,2 & 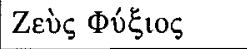 & \\
\hline II, 22,2 & Zev̀ $\mathrm{M \eta} \chi \alpha v \varepsilon u ́ \varsigma$ & Lieu du serment des héros de Troie \\
\hline II, 24,3 & Zzù $\Lambda \alpha \rho ı \alpha \hat{\imath} 0 \varsigma$ & Dédicace de Sthenelos, à son retour de Troie \\
\hline
\end{tabular}

Pour Zeus, les systèmes légendaires les plus utilisés sont le cycle thébain et le cycle de la guerre de Troie. Le fait que les récits destinés à rendre compte des cultes des divinités poliades sont nettement séparés des cycles de Phoroneus et de Danaos pourrait indiquer que les Argiens ressentaient comme distinctes les divinités occupant les acropoles.

95 Seule Athéna Saïtis à Lerne (PAUSANIAS, II, 37, 8) entre dans le cycle de Danaos.

96 Sans entrer dans le détail d'une étude qui réclamerait un développement à part, qu'il me soit permis d'exprimer ici mon profond désaccord avec la théorie développée par P. MARCHETTI, Recberches sur les mytbes et la topograpbie d'Argos. III Le téménos de Zeus, in BCH 118 (1994), p. 142-153. L'identification d'une partie considérable de l'agora avec un hypothétique téménos de Zeus dont le temple de Zeus Néméen n'aurait constitué qu'un élément ne repose sur aucun argument positif, mais sur l'intuition qu'il existerait un «commun dénominateur " entre les curiosités décrites par Pausanias, en l'occurrence les autels et statues consacrés à Zeus. En fait, Pausanias décrit le temple de Zeus Néméen à mi-chemin entre le temple d'Apollon Lycien, qu'il convient de chercher là où $\mathrm{P}$. Marchetti voudrait mettre le temenos de Zeus ( $c f$. M. PIÉRART, $D e$ l'endroit ou l'on abritait quelques statues d'Argos et de la vraie nature du feu de Pboroneus, in $B C H, 117$ [1993], p. 609-613) et le temenos de Phoroneus, qui faisait encore l'objet d'un culte du temps de Pausanias (II, 20,3). L'un et l'autre lieu de culte se trouvaient au nord de l'agora, de l'autre côté de la rue qui bordait l'agora dans sa partie nord et conduisait à la porte d'Ilythie, comme il ressort de l'examen de plusieurs indices (voir provisoirement M. PIÉRART, op. cit. [n. 4], p. 132133). Je reviendrai prochainement sur cette question. 


\section{Conclusions}

On chercherait en vain des traces positives d'un rôle joué par le bouclier dans le rituel d'Héra. Les légendes qui le concernent ont été remodelées après que l'usage s'est établi d'offrir un bouclier comme prix unique des concours d'Héra, ce qui n'était pas encore le cas à l'époque classique. La légende du bouclier d'Euphorbe est née ailleurs qu'à Argos et n'y a sans doute été adaptée qu'assez tard.

En revanche, le rite du bouclier attesté par Callimaque a toutes les chances d'être ancien. Ce bouclier, qui symbolisait la protection accordée par Athéna sur sa ville, a été associé dans la légende à deux moments de l'histoire d'Argos. Le récit de la fuite du prêtre de Pallas, Eumédès, à l'époque du Retour des Héraclides prouvait que la déesse approuvait l'action de ces derniers. Avec le succès des poèmes du Cycle, après que les Argiens eurent acquis la conviction qu'ils possédaient le Palladion et le xoanon de Zeus ramenés de Troie par leurs rois, l'idée s'imposa que le bouclier d'Athéna était celui de Diomède, un héros que la déesse aimait au point de lui accorder l'immortalité. Mais si les Argiens ont admis que Diomède avait été l'un de leurs rois, ils ne semblent pas lui avoir fait de place en dehors du culte d'Athéna, ce qui pourrait être un indice en faveur du caractère secondaire de la tradition. Nous n'avons pas les moyens de remonter plus haut dans le temps.

Une approche du panthéon argien par la mythologie, qui s'articule autour des généalogies mythiques, a pour avantage de mettre en valeur les réseaux de relations établies entre les divinités de l'Argolide et de permettre de mieux appréhender le sens qu'on a donné aux cultes qu'on leur rendait. J'ai essayé de montrer ailleurs l'intérêt des classifications généalogiques pour la disposition topographique des sanctuaires et des tombes héroïques. La prise de possession symbolique du territoire obéit, elle aussi, à certaines règles. Il y a interaction entre les divers phénomènes et l'étude de ces relations nous aide à reconstituer la mentalité des Argiens.

Université de Fribourg

Marcel PIÉRART

Séminaire d'Histoire ancienne

16 , rue Pierre-Aeby

$\mathrm{CH}-1700$ FRIBOURG 